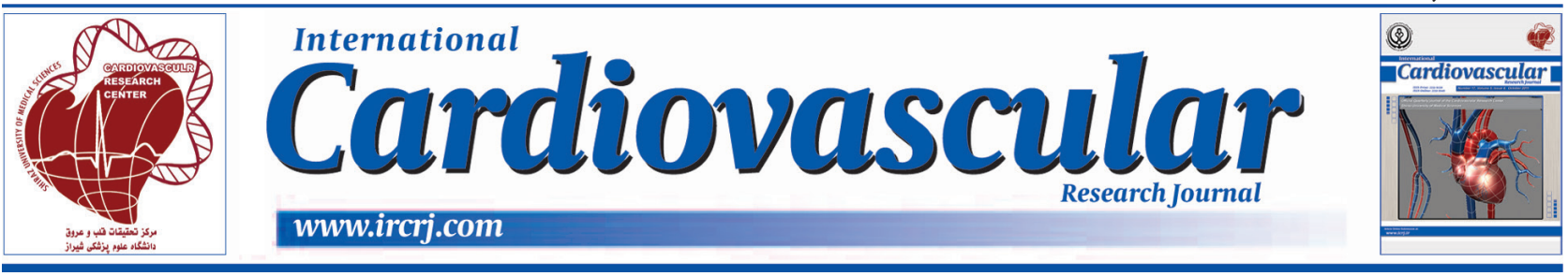

\title{
Right Coronary Artery Ostial Avulsion and Aortic Dissection during Right Coronary Artery Angioplasty in a Dwarf Woman, a Case Report
}

\author{
Mohammad Ali Ostovan ${ }^{1}$ and Pooyan Dehghani ${ }^{1, *}$
}

${ }^{1}$ Cardiovascular Research Center, Cardiology Department, Shiraz University of Medical Sciences, Shiraz, IR Iran

\begin{tabular}{|c|c|}
\hline A R T I C L E I N F O & A B S T R A C T \\
\hline $\begin{array}{l}\text { Article Type: } \\
\text { Case Report }\end{array}$ & $\begin{array}{l}\text { Iatrogenic aortocoronary dissection and ostial coronary avulsion are rare and } \\
\text { devastating complications of Percutaneous Coronary Intervention (PCI), which mandate }\end{array}$ \\
\hline $\begin{array}{l}\text { Article History: } \\
\text { Received: 06 Jul } 2014 \\
\text { Accepted: } 11 \text { Mar } 2015\end{array}$ & $\begin{array}{l}\text { in a dwarf woman with chronic total occlusion of the vessel during PCI and discussed } \\
\text { about the results and pitfalls. }\end{array}$ \\
\hline
\end{tabular}

Keywords:

Percutaneous Coronary Intervention

Coronary Artery Dissection

Dwarfism

Implication for health policy/practice/research/medical education:

This case presentation can help interventionists and cardiologists get more familiar with therapeutic modalities and complications in case of dwarfism (as an example of patients with loose connective tissues) with chronic total occlusion of the right coronary artery.

\section{Introduction}

Aortoostial dissection is a rare and potentially lifethreatening complication of Percutaneous Coronary Intervention (PCI). Coronary dissection is a trigger for progressive extension of the dissection into the coronary ostium and sinus of valsalva, which finally propagates to the ascending aorta (1). The prognosis and treatment of choice for this entity have not been well described and both surgical intervention and ostial coronary stenting have been reported in the literature $(2,3)$.

\section{Case Presentation}

A 60-year-old woman, a case of congenital dwarfism $(75 \mathrm{~cm}$ height) with two vessel disease (Left Anterior Descending (LAD) artery midpart significant lesion, Right Coronary Artery (RCA) proximal Chronic Total Occlusion (CTO)) was referred for PCI. The patient was in Canadian cardiovascular society grade III of angina pectoris and had a past history of

*Corresponding author: Pooyan Dehghani, Cardiology Department, Nemazee Hospital, Nemazee Square, Shiraz, Iran. Cellphone: +98-9173177631, E-mail:p.dehghani@gmail.com dyslipidemia and old inferior myocardial infarction.

LAD was targeted first. After $2 \mathrm{~mm}$ balloon dilation, there was a long dissection that was covered with a $2.5 \times 23$ Cypher stent. Although the RCA total cutoff was long and started from near the ostium (Figure 1), we decided to try for opening the occluded vessel. Wire passed very easily from CTO (subintimal), but it was in true lumen distally. Balloon inflation with $2 \times 15$ balloon was done. A long spiral dissection appeared, which was covered distally by two long bare stents (no drug eluting stents were available). Due to fragility of the patient's vessels, RCA was dissected from ostium by the guiding catheter. Therefore, we decided to deploy another stent in RCA ostium just to save the vessel acutely. However, the patient became hypotensive with chest pain at this time. RCA injection showed extensive contrast penetration and staining in aortic wall until the end of aortic arch and outpouring of contrast from the end of the ascending aorta into the pericardium (Figure 2).

Pericardial tap was done quickly and pigtail catheter was inserted. The patient's hemodynamics stabilized, but repeated aortography showed contrast penetration into 


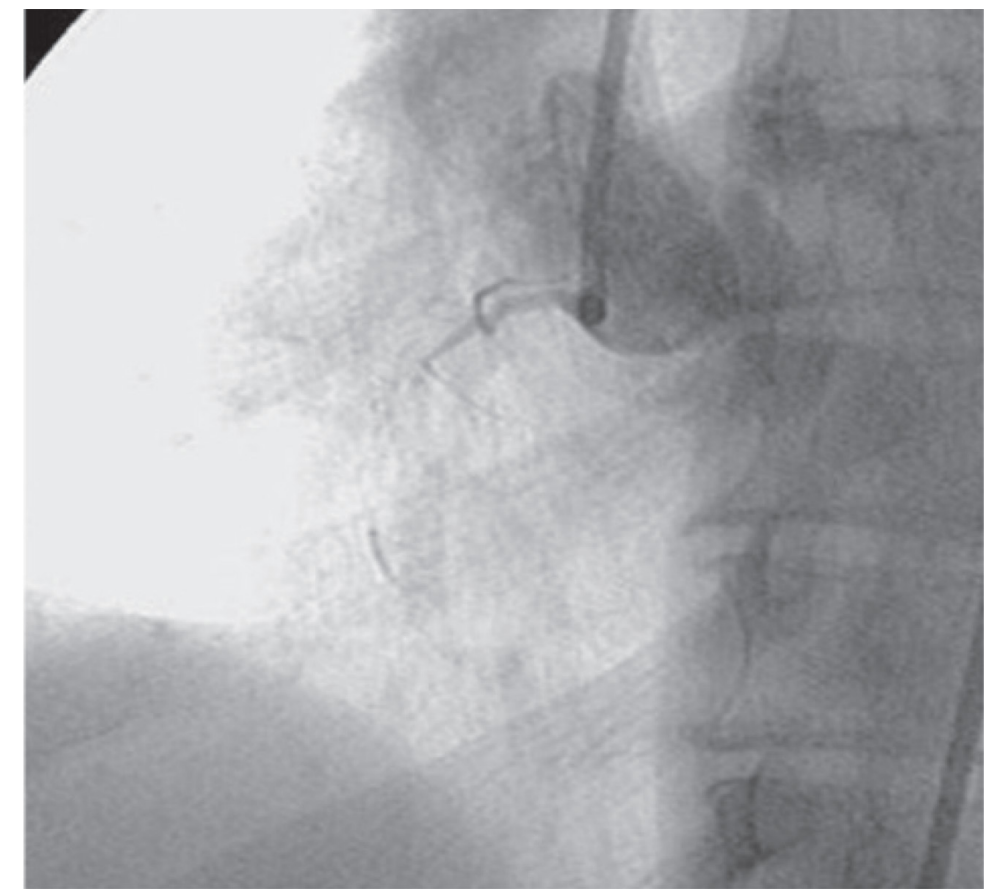

Figure 1. The Total Cut-Off Right Coronary Artery

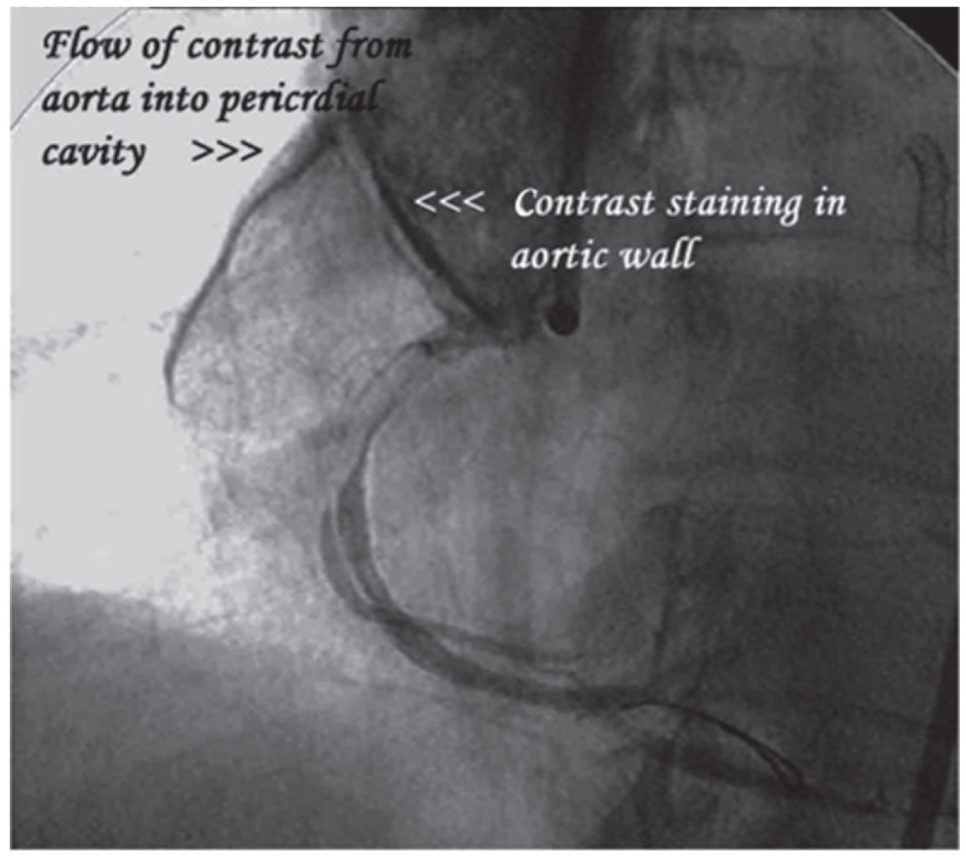

Figure 2. The Complicated Percutaneous Coronary Intervention

the aortic wall and the pericardium. Hence, we decided to send the patient to operating room. In the operating room, an incomplete avulsion of RCA ostium with minimal hemopericardium was found, but without gross aortic dissection. Therefore, RCA was sutured and very small Patent Ductus Arteriosus (PDA) and Right Ventricular (RV) branch were grafted. Unfortunately, the patient could not be weaned off the bypass pump due to RV dysfunction and died in the operating room.

\section{Discussion}

There are several management modalities when PCI is complicated by aortoostial dissection with propagation of hematoma towards the ascending aorta. If the dissection is just limited to the sinus of valsalva, conservative management is advised as the situation usually resolves (4). However, if the extension of the dissection is above the sinus of valsalva, either percutaneous or surgical intervention is mandatory $(1,2,5)$. There are several reports regarding successful performance of percutaneous interventions on aortoostial dissections with limited aortic involvement by stenting the coronary ostium with good results. Nonetheless, dissections involving more than $40 \mathrm{~mm}$ of the ascending aorta usually require surgical interventions (6). Coronary stenting is another possible option to avoid surgical intervention in some patients. Considering our case, there are several points to be mentioned. First of all, patients with connective tissue diseases, such as dwarfism, 
have fragile vessels and are not good candidates for PCI. When the fragility of the vessel was seen during LAD stenting, attempt for RCA chronic total occlusion should not have been made. The second point is that aortic contrast staining was due to ostial perforation not extensive aortic dissection and putting a covered stent in RCA ostium might have solved the problem or at least it was worth a trial. Finally, when the patient's hemodynamic was stabilized with a simple pericardial tap, it was better to wait rather than rushing the patient to the operating room.

\section{Acknowledgements}

There is no acknowledgements.

\section{Authors' Contribution}

Both authors contributed to study design, acquisition of data, drafting of the manuscript, critical revision of the study, and study supervision.

\section{Financial disclosure}

The authors declare that there is no conflict of interests.

\section{Funding/Support}

There is no funding/support.

\section{References}

1. Perez-Castellano N, Garcia-Fernandez MA, Garcia EJ, Delcan JL. Dissection of the aortic sinus of Valsalva complicating coronary catheterization: cause, mechanism, evolution, and management. Cathet Cardiovasc Diagn. 1998;43(3):273-9.

2. Brown RA, Purcell I. Aortocoronary dissection complicating primary angioplasty. J Invasive Cardiol. 2009;21(8):E145-6.

3. Sarkis A, Maaliki S, Haddad A, Hatem J, Ghanem G. An unusual complication of coronary angiography: bidirectional dissection of the right coronary artery and the ascending aorta. Int J Cardiol. 2009;132(1):e20-2.

4. Carter AJ, Brinker JA. Dissection of the ascending aorta associated with coronary angiography. Am J Cardiol. 1994;73(12):922-3.

5. Shorrock D, Michael TT, Patel V, Kotsia A, Rangan BV, Abdullah $\mathrm{SA}$, et al. Frequency and outcomes of aortocoronary dissection during percutaneous coronary intervention of chronic total occlusions: a case series and systematic review of the literature. Catheter Cardiovasc Interv. 2014;84(4):670-5.

6. Dunning DW, Kahn JK, Hawkins ET, O’Neill WW. Iatrogenic coronary artery dissections extending into and involving the aortic root. Catheter Cardiovasc Interv. 2000;51(4):387-93. 